\title{
PRELIMINARY QUALITY ANALYSIS OF GF-7 SATELLITE LASER ALTIMETER FULL WAVEFORM DATA
}

\author{
Guoyuan.Li ${ }^{\text {a,b,c,*, Jinquan. Guo }}{ }^{\mathrm{a}, \mathrm{c}}$, Xinming.Tang ${ }^{\mathrm{a}, \mathrm{b}}$, Fanghong.Ye $^{\mathrm{a}}$, Zhiqiang.Zuo ${ }^{\mathrm{a}, \mathrm{d}}$, Zhao.Liu ${ }^{\mathrm{a}}$,Jiyi.Chen $^{\mathrm{a}}$, Yucai.Xue ${ }^{\mathrm{a}}$ \\ ${ }^{a}$ Land Satellite Remote Sensing Application Center, MNR, Beijing, China- (ligy_lasac@foxmail.com; tangxm@lasac.cn; \\ yefh@lasac.cn; liuz@lasac.cn; chenjx@lasac.cn; xueyc@lasac.cn); \\ b Jiangsu Center for Collaborative Innovation in Geographical Information Resource Development and Application, Nanjing, China \\ c School of Geomatics, Liaoning Technical University, Fuxin, China-(942132720@qq.com); \\ d School of Electric Information of Wuhan University, Wuhan, China - (zhiqiang_zuo@whu.edu.cn)
}

\section{Commission I, WG I/2}

KEY WORDS: GF-7, Satellite Laser Altimeter, Full Waveform Data, Quality Evaluation

\begin{abstract}
:
The full-waveform data is the core data of GaoFen-7 (GF-7) satellite laser altimeter, and evaluation of waveform data quality is an important step and premise for satellite laser altimetry and quality control. In this paper, the full waveform data quality assessment and analysis of GF-7 laser altimeter is implemented during the period of on-orbit experiment, and the real waveform data of many orbits is used to quantitatively describe the characteristic parameters of the transmitted waveform and the signal-to-noise ratio (SNR), and the result of two beam lasers is compared. The conclusion is validated that the GF-7 laser altimeter can obtain effective waveform data and the echo waveform availability of the experimental data is approximate $72.59 \%$, moreover, the quality of beam 1 is slightly better than that of the beam 2. The laser temperature is an important indication of the quality of transmitted waveform according to the SNR changing. The good SNR value of the waveform and small footprint size will be helpful for the terrain information extraction and analysis, although the repetition frequency is low.
\end{abstract}

\section{INTRODUCTION}

As an active remote sensing, laser altimeter has been concerned to load on the satellite to obtain the high precision elevation information (Tang et al., 2017). The United Sates has launched two laser altimetry satellites, ICESat (Ice, Cloud and land Elevation Satellite) and ICESat-2, in 2003 and 2018 respectively, and based on the laser altimetry data collected by these two satellites, especially the waveform data of ICESat (Brenner et al., 2011), much research and application has been carried out, including the establishment of the theoretical model of laser altimeter, the decomposition method of echo waveform(Li et al., 2019), filtering method of the waveform(Wang et al.,2019), monitoring of the water level in lakes(Wang et al.,2012; Zhang et al.,2011), analysis of elevation changes in polar ice caps (Kääb et al.,2012; Bolch et al.,2013), estimation of forest biomass(Xing et al.,2010; Harding and David,2005), and acquisition of ground high precision control points (Carabajal et al., 2010; Li et al., 2017).

In 2016, China launched the ZY3-02 satellite, which was equipped with the first experimental laser altimeter in China $(\mathrm{Li}$ et al., 2017). It was mainly used to test the function and performance of the laser altimeter, and has provided important reference for the next laser altimetry satellites although it did not record the full-waveform data. GF-7 Satellite (GF-7) is the first civilian submeter-class optical transmission stereo mapping satellite of China, which has been successfully launched on November $3^{\text {rd }}, 2019$. Along with high resolution stereo cameras, a two-beam laser altimeter with full waveform sampling and recording function is also equipped on the GF-7 to obtain high accuracy elevation control points.

In this paper, a total of 10 orbits laser altimetry data obtained by GF-7 satellite during the period of the on-orbit test are used to evaluate the waveform data quality. The waveform characteristic parameters, SNR (signal-to-noise ratio) and other relative parameters are calculated and compared in the experiment, and the results are analysed to summarize the evaluation results of the waveform data quality of GF-7 laser altimeter.

\section{GF-7 SATELLITE AND LASER ALTIMETER}

\subsection{The basic parameters of GF-7}

The GF-7 satellite has two stereo camera and two laser beam, illustrated in Figure 1. The viewing angle of forward and backward camera is $26^{\circ}$ and $-5^{\circ}$ respectively, and the swath width is about $20 \mathrm{~km}$ with resolution better than $0.8 \mathrm{~m}$.

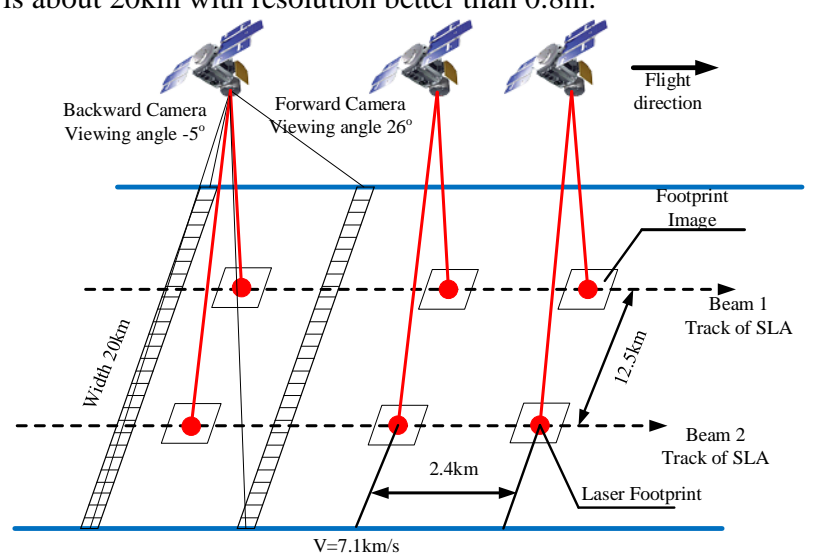

Figure 1. Working mode of GF-7 satellite

And the inclination angle of two laser beams are about 0.7 degrees on the vertical plane along the left and right of nadir pointing direction respectively, and the laser wavelength is $1064 \mathrm{~nm}$, with a divergence angle of [30urad,35urad], which is better than the

\footnotetext{
* Corresponding author: ligy_lasac@foxmail.com;
} 
designed value 60urad and corresponds to surface laser spot in a diameter of $[15 \mathrm{~m}, 17.5 \mathrm{~m}] @ 500 \mathrm{~km}$. The sampling interval of the full-waveform is $0.5 \mathrm{~ns}$, and the corresponding distance resolution is $0.075 \mathrm{~m}$. In order to adapt to the echo intensity of difference surface reflectance, the full-waveform data are recorded in two kind of modes-high and low gain, which are showed in Table 1.

\begin{tabular}{c|c}
\hline Parameter & Value \\
\hline Wavelength & $1064 \mathrm{~nm}$ \\
Beam number & 2 \\
Frequency & $3 \mathrm{~Hz} / 6 \mathrm{~Hz}$ \\
Laser divergence angle & {$[30 \mathrm{urad}, 35 \mathrm{urad}]$} \\
Footprint diameter & {$[15 \mathrm{~m}-17.5 \mathrm{~m}] @ 500 \mathrm{~km}$} \\
Waveform Sampling & $2 \mathrm{GHz} / 0.5 \mathrm{~ns}$ \\
interval & $10 \mathrm{bits}$ \\
Waveform quantization bits & High/Low gain \\
Waveform sampling mode & $5-7 \mathrm{~ns}$ \\
Pulse width of transmitting & $3.2 \mathrm{~m}$ \\
waveform & $550 * 550 \mathrm{pixel}$ \\
\hline
\end{tabular}

Table. 1 Parameters of GF-7 satellite laser altimeter

\subsection{Experimental data}

In this paper, a total number of 10-orbit laser data obtained during the period of on-orbit test of GF-7 were statistically analysed. These 10-orbit laser waveform data were collected, and the laser footprints are distributed in some regions of North America, Europe, Africa, Oceania, Asia and a few of Antarctica. The number of laser points in each orbit is shown in Table 2, and when the proportion of effective echo is low, it means that laser propagation is blocked by the thick cloud, with no echo waveform detected by the receiver.

\begin{tabular}{ccccc}
\hline $\begin{array}{c}\text { Orbit } \\
\text { No. }\end{array}$ & $\begin{array}{c}\text { Number of } \\
\text { Transmitte } \\
\text { d laser } \\
\text { pulses }\end{array}$ & $\begin{array}{c}\text { Number of } \\
\text { Received } \\
\text { laser } \\
\text { pulses }\end{array}$ & $\begin{array}{c}\text { Ratio of } \\
\text { effective } \\
\text { echoes }\end{array}$ & $\begin{array}{c}\text { Acquisition } \\
\text { time }\end{array}$ \\
\hline 117 & 1224 & 469 & $38.32 \%$ & 2019.11 .11 \\
154 & 1202 & 958 & $79.70 \%$ & 2019.11 .13 \\
245 & 750 & 746 & $99.47 \%$ & 2019.11 .19 \\
246 & 682 & 615 & $90.18 \%$ & 2019.11 .19 \\
282 & 1890 & 1669 & $88.31 \%$ & 2019.11 .22 \\
320 & 1350 & 1317 & $97.56 \%$ & 2019.11 .24 \\
321 & 1442 & 541 & $37.52 \%$ & 2019.11 .24 \\
337 & 1606 & 1553 & $96.70 \%$ & 2019.11 .25 \\
344 & 948 & 223 & $23.52 \%$ & 2019.11 .26 \\
358 & 1652 & 1161 & $70.28 \%$ & 2019.11 .26 \\
Total & $\mathbf{1 2 7 4 6}$ & $\mathbf{9 2 5 2}$ & $\mathbf{7 2 . 5 9 \%}$ & \\
\hline
\end{tabular}

Table 2. Orbital number, number of laser points and acquisition time of experimental data

\section{WAVEFORM QUALITY EVALUATION METHOD}

\subsection{Waveform background noise parameters}

The noise of waveform data is mainly composed of the system noise of the laser itself and the solar background noise. And different terrain features may impose different influence on the waveform, here, we make an assessment merely on the system noise of the laser.

The background noise was calculated from the intensity of the sampling point in the area with no effective waveform in the GF-
7 waveform data. The transmitted waveform length of GF-7 laser altimeter is $200 \mathrm{~ns}$, and a total number of 400 sampling points are obtained with a sampling frequency of $2 \mathrm{GHz}$. The last quarter of transmitted waveform, that is, beginning from 150ns, sampling points of 50ns are used to calculate the waveform background noise. The received waveform length is $400 \mathrm{~ns}$, corresponding to 800 sampling points, and the last $50 \mathrm{~ns}$ waveform data are used to calculate the background noise of received waveform

$$
\begin{aligned}
& m_{N}=\sum_{t}^{T} \frac{V_{i}}{(T-t)} \\
& \sigma_{N}=\sqrt{\sum_{t}^{T} \frac{\left(V_{i}-m_{N}\right)^{2}}{(T-t)-1}}
\end{aligned}
$$

Where $t$ and $T$ are beginning and ending time coordinates of the range respectively. For the transmitted waveform, the $t=$ $150 \mathrm{~ns}$ and $T=200 \mathrm{~ns}$. The $V_{i}$ is the intensity value of the waveform at the moment $t$. And for the receive waveform, $t=$ $350 \mathrm{~ns}$ and $T=400 \mathrm{~ns}$.

\subsection{Waveform gaussian characteristic parameters}

The waveform data of the satellite laser altimeter is approximately a gaussian function, which is used to fit the waveform to obtain the gaussian characteristic parameters, such as amplitude value of waveform. The Gaussian model formula is as follows,

$$
V(t)=\sum_{i=1}^{N} A_{i} e^{-\frac{\left(t-\mu_{i}\right)^{2}}{2 \sigma_{i}^{2}}}
$$

Where $A_{i}$ is the amplitude value of $\mathrm{i}$-th gaussian component, $\mu_{i}$ is the peak location of the $\mathrm{i}$-th gaussian component, and $\sigma_{i}$ is the root mean square (RMS) pulse width of the i-th gaussian component.

Firstly, the effective waveform is selected out using the above background noise value plus four times the standard deviation as the threshold, and the gaussian fitting is carried out, using the nonlinear least square method for iteration to ensure the fitting accuracy. Finally, the gaussian parameters are extracted.

\subsection{Waveform kurtosis and skewness}

For the transmitted waveform, the shape should be almost the same and viewed as one Gaussian function distribution during the working period. The Kurtosis of the waveform is an indicator to reflect the sharp or flat degree at the top of distribution curve of waveform intensity, and the skewness of the waveform is a measure of the skew direction and degree of the statistical data distribution, which can directly show the asymmetric degree of the data distribution. The arithmetic mean, standard deviation values and skewness coefficients of two different data sets sometimes may be same, however, the sharp degree may be different. The Kurtosis and Skewness of a waveform data set with $\mathrm{n}$ samples is as follows,

$$
\begin{gathered}
S K=\frac{n \sum_{i=1}^{n}\left(x_{i}-\bar{x}\right)^{3}}{(n-1)(n-2) S D^{3}} \\
K=\frac{1}{n S D^{2}} \sum_{i=1}^{n}\left(x_{i}-\bar{x}\right)^{4}
\end{gathered}
$$

Where $n$ is the total number of samples, and $S D$ is the variance of the waveform as $S D=\frac{1}{n} \sum_{i=1}^{n}\left(x_{i}-\bar{x}\right)^{2}(\bar{x}$ is the mean value of waveform samples).

The Kurtosis value of a standard gaussian distribution is 3 ( $K=$ 3 ). When $K>3$, there is a sharp peak on top of the statistical data distribution curve, indicating that the data is more concentrated. And conversely, there is a flat peak of the data distribution curve corresponding to a more dispersed distribution. The Skewness value of the standard gaussian is $0(S K=0)$. When $S K>0$, it can be considered that the statistical data has a right-skewed distribution, that is, it shows a trailing distribution on the right, and the greater the $S K$ is, the higher degree of right 
deviation is. Conversely, the statistical data has a left-skewed distribution with $S K<0$, showing a trailing distribution on the left, and the smaller the $S K$ is, the higher the degree of left deviation is.

\subsection{Waveform signal-to-noise ratio (SNR)}

The SNR of waveform is calculated based on the mean value and standard deviation of background noise (Nie et al.,2014; Li, 2017), and the formula is as follows,

$$
\mathrm{SNR}=10 \lg \frac{I_{\max }-m_{N}}{\sigma_{N}}
$$

Where the $I_{\max }$ is maximum value of the waveform intensity, and $m_{N}$ is the mean value of background noise, $\sigma_{N}$ is the standard deviation of the waveform noise. This method does not need to fit the waveform to get a more accurate SNR, and is computational convenient.

\section{RESULTS AND ANALYSIS}

\subsection{Results of the transmitted waveform experiment}

According to the above-mentioned quality evaluation parameters, the results of the experiments are shown in Table 3 and Figure 2.

\begin{tabular}{|c|c|c|c|c|c|c|c|c|c|c|}
\hline \multirow{2}{*}{$\begin{array}{l}\text { Orbit } \\
\text { Number }\end{array}$} & \multirow{2}{*}{ Laser } & \multirow{2}{*}{$\begin{array}{l}\text { Gain } \\
\text { mode }\end{array}$} & \multicolumn{2}{|c|}{$\begin{array}{c}\text { Background } \\
\text { noise }(\mathrm{mV})\end{array}$} & \multirow[t]{2}{*}{ SNR } & \multirow{2}{*}{$\underset{(\mathrm{mV})}{\text { Amplitude }}$} & \multirow{2}{*}{$\begin{array}{c}\text { Peak } \\
\text { Location(ns) }\end{array}$} & \multirow{2}{*}{$\begin{array}{c}\text { Pulse } \\
\text { width(ns) }\end{array}$} & \multirow{2}{*}{ Skewness } & \multirow{2}{*}{ Kurtosis } \\
\hline & & & Mean & Std & & & & & & \\
\hline \multirow{4}{*}{117} & \multirow{2}{*}{ Laser1 } & $\mathrm{HG}^{*}$ & 81.951 & 1.935 & 20.084 & 112.220 & 217.053 & 6.772 & 0.168 & 2.705 \\
\hline & & $\mathrm{LG}^{*}$ & 85.846 & 0.886 & 21.204 & 65.915 & 207.093 & 6.240 & 0.482 & 2.644 \\
\hline & \multirow{2}{*}{ Laser2 } & $\mathrm{HG}$ & 88.625 & 2.628 & 17.332 & 77.895 & 215.118 & 6.054 & 0.060 & 2.678 \\
\hline & & LG & 87.117 & 0.956 & 18.431 & 36.173 & 205.197 & 5.207 & 0.411 & 2.592 \\
\hline \multirow{4}{*}{154} & \multirow{2}{*}{ Laser1 } & HG & 82.430 & 1.886 & 19.866 & 103.932 & 216.837 & 6.867 & 0.144 & 2.701 \\
\hline & & LG & 86.200 & 0.829 & 21.078 & 60.568 & 206.863 & 6.407 & 0.439 & 2.634 \\
\hline & \multirow{2}{*}{ Laser2 } & HG & 89.201 & 2.337 & 17.603 & 73.705 & 214.842 & 6.071 & 0.065 & 2.679 \\
\hline & & LG & 87.418 & 0.924 & 18.351 & 34.132 & 204.914 & 5.176 & 0.410 & 2.578 \\
\hline \multirow{4}{*}{245} & \multirow{2}{*}{ Laser1 } & HG & 82.292 & 1.988 & 19.121 & 91.821 & 216.201 & 6.827 & 0.113 & 2.680 \\
\hline & & LG & 86.137 & 0.868 & 20.354 & 53.562 & 206.207 & 6.403 & 0.378 & 2.613 \\
\hline & \multirow{2}{*}{ Laser2 } & HG & 89.212 & 2.499 & 17.250 & 72.115 & 214.742 & 6.014 & 0.053 & 2.672 \\
\hline & & LG & 87.423 & 0.903 & 18.384 & 38.746 & 204.818 & 5.173 & 0.406 & 2.575 \\
\hline \multirow{4}{*}{246} & \multirow{2}{*}{ Laser1 } & HG & 82.193 & 2.021 & 19.412 & 99.766 & 216.500 & 6.744 & 0.138 & 2.690 \\
\hline & & LG & 85.883 & 0.885 & 20.696 & 58.725 & 206.525 & 6.252 & 0.452 & 2.632 \\
\hline & \multirow{2}{*}{ Laser2 } & HG & 88.588 & 2.447 & 17.740 & 80.218 & 215.222 & 6.104 & 0.074 & 2.681 \\
\hline & & LG & 86.821 & 0.913 & 18.735 & 37.230 & 205.306 & 5.242 & 0.439 & 2.591 \\
\hline \multirow{2}{*}{282} & \multirow{2}{*}{ Laser1 } & HG & 82.701 & 1.984 & 19.278 & 95.315 & 216.388 & 6.834 & 0.132 & 2.685 \\
\hline & & LG & 86.074 & 0.865 & 20.544 & 55.781 & 206.394 & 6.40 & 0.426 & 2.619 \\
\hline \multirow{4}{*}{321} & \multirow{2}{*}{ Laser1 } & HG & 82.43 & 2.071 & 19.015 & 93.349 & 216.230 & 6.789 & 0.116 & 2.680 \\
\hline & & LG & 86.144 & 0.834 & 20.629 & 54.728 & 206.231 & 6.369 & 0.429 & 2.616 \\
\hline & & HG & 88.838 & 2.532 & 17.506 & 78.394 & 215.138 & 6.064 & 0.065 & 2.678 \\
\hline & Laser2 & LG & 87.228 & 0.953 & 18.465 & 36.427 & 205.216 & 5.199 & 0.416 & 2.592 \\
\hline & & HG & 82.22 & 1.947 & 19.429 & 96.795 & 216.400 & 6.803 & 0.139 & 2.688 \\
\hline & Laser1 & LG & 86.016 & 0.823 & 20.853 & 56.763 & 206.412 & 6.344 & 0.452 & 2.624 \\
\hline 337 & & $\mathrm{HG}$ & 88.564 & 2.496 & 17.691 & 80.859 & 215.287 & 6.104 & 0.069 & 2.685 \\
\hline & Laser2 & LG & 87.078 & 0.944 & 18.614 & 37.446 & 205.380 & 5.235 & 0.426 & 2.584 \\
\hline & & HG & 82.52 & 2.040 & 18.966 & 90.768 & 216.073 & 6.775 & 0.139 & 2.679 \\
\hline & Laser1 & LG & 86.089 & 0.895 & 20.242 & 53.214 & 206.036 & 6.311 & 0.452 & 2.617 \\
\hline 344 & & HG & 88.955 & 2.534 & 17.306 & 74.469 & 214.882 & 6.045 & 0.069 & 2.676 \\
\hline & ser2 2 & LG & 87.273 & 0.942 & 18.315 & 34.623 & 204.960 & 5.176 & 0.426 & 2.583 \\
\hline & & HG & 82.364 & 2.092 & 18.901 & 92.026 & 216.129 & 6.798 & 0.110 & 2.675 \\
\hline 358 & $\operatorname{asch}$ & LG & 86.161 & 0.861 & 20.417 & 53.823 & 206.118 & 6.369 & 0.416 & 2.618 \\
\hline 358 & & HG & 88.942 & 2.528 & 17.378 & 75.631 & 215.007 & 6.052 & 0.060 & 2.674 \\
\hline & Laser2 & LG & 87.265 & 0.909 & 18.539 & 35.226 & 205.089 & 5.209 & 0.421 & 2.586 \\
\hline
\end{tabular}

Table 3 . The calculation results of the transmitted waveform during different time and orbits

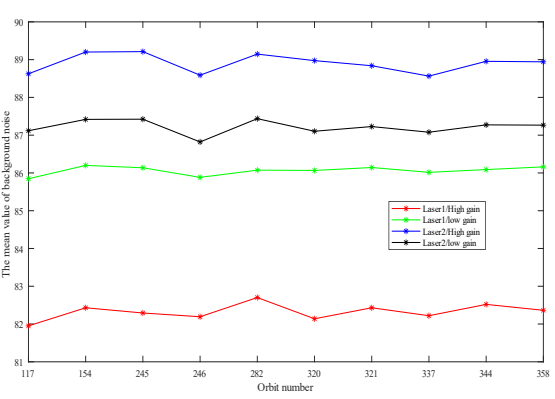

(a) Variation of the mean value of $\mathrm{BN}$

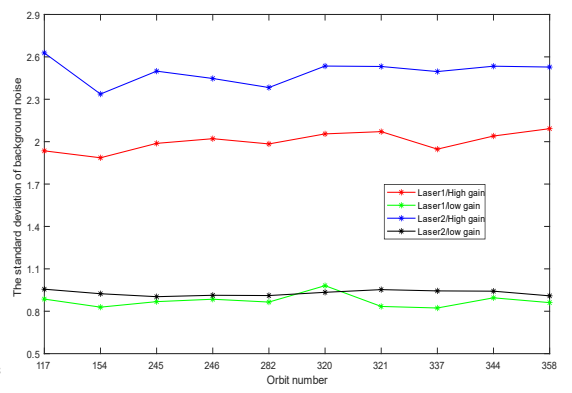

(b) Variation of the standard deviation of BN

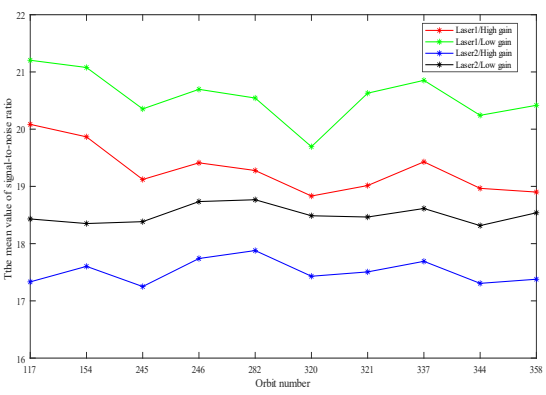

(c) Variation of the mean value of SNR 


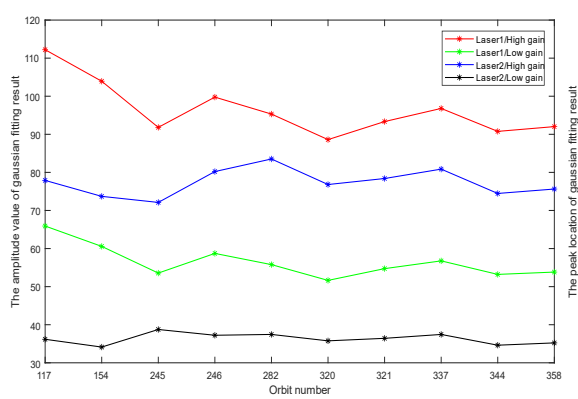

(d) Variation of the amplitude value

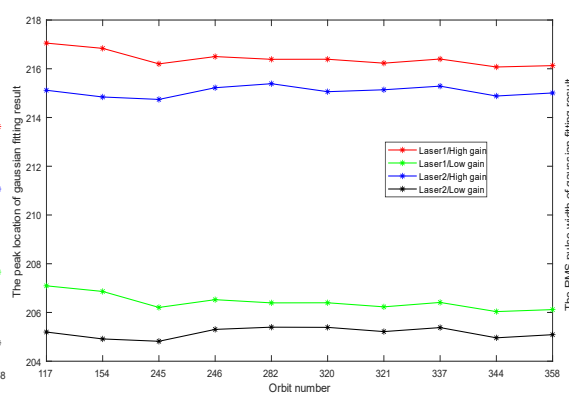

(e) Variation of the peak location

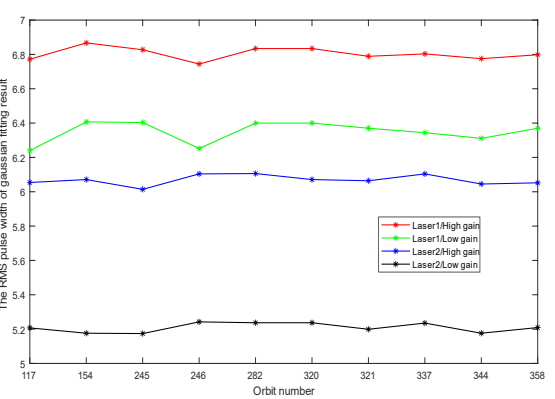

(f) Variation of the pulse width

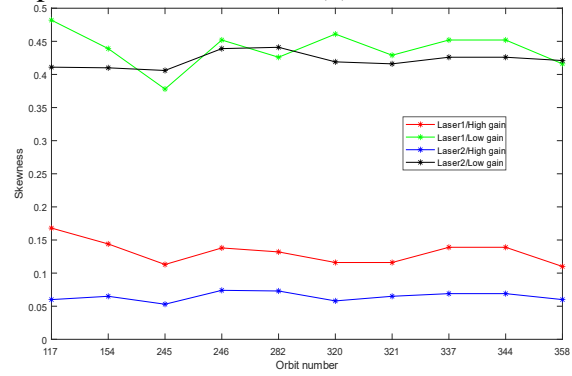

(g) Variation of the Skewness

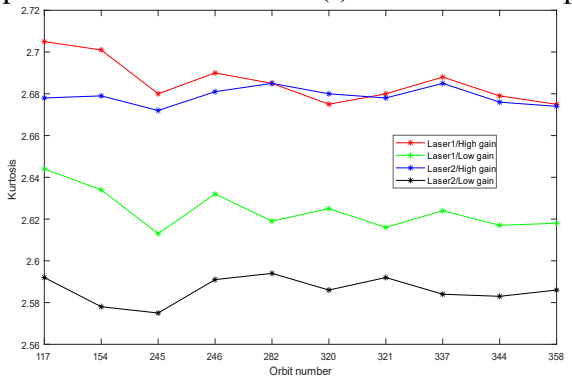

(h) Variation of the Kurtosis

Figure 2. Analysis results of quality parameters of transmitted waveform

\subsection{Experiment results of received waveform}

The calculated result of the background noise parameters and SNR of the received waveform of the 10 orbits data has been showed as Table 4 and Figure 3.

\begin{tabular}{|c|c|c|c|c|c|}
\hline \multirow{2}{*}{$\begin{array}{c}\text { Orbit } \\
\text { Number }\end{array}$} & \multirow[t]{2}{*}{ Laser } & \multirow{2}{*}{$\begin{array}{l}\text { Gain } \\
\text { mode }\end{array}$} & \multicolumn{2}{|c|}{$\begin{array}{c}\text { Background } \\
\text { noise }(\mathrm{mV})\end{array}$} & \multirow{2}{*}{$\begin{array}{c}\text { Mean of } \\
\text { SNR }\end{array}$} \\
\hline & & & Mean & Std & \\
\hline \multirow{4}{*}{117} & \multirow{2}{*}{ Laser 1} & $\mathrm{HG}^{*}$ & 83.667 & 1.935 & 24.609 \\
\hline & & LG* & 87.669 & 0.886 & 25.137 \\
\hline & \multirow{2}{*}{ Laser2 } & HG & 94.523 & 2.628 & 22.269 \\
\hline & & LG & 90.102 & 0.956 & 22.868 \\
\hline \multirow{4}{*}{154} & \multirow{2}{*}{ Laser1 } & $\mathrm{HG}$ & 83.698 & 1.886 & 24.437 \\
\hline & & LG & 87.760 & 0.829 & 25.096 \\
\hline & \multirow{2}{*}{ Laser2 } & $\mathrm{HG}$ & 94.728 & 2.337 & 21.820 \\
\hline & & LG & 90.154 & 0.924 & 22.133 \\
\hline \multirow{4}{*}{245} & \multirow{2}{*}{ Laser1 } & $\mathrm{HG}$ & 84.694 & 1.988 & 24.826 \\
\hline & & LG & 87.372 & 0.868 & 24.307 \\
\hline & \multirow{2}{*}{ Laser2 } & $\mathrm{HG}$ & 94.825 & 2.499 & 22.204 \\
\hline & & LG & 89.867 & 0.903 & 21.559 \\
\hline \multirow{4}{*}{246} & \multirow{2}{*}{ Laser1 } & $\mathrm{HG}$ & 84.625 & 2.021 & 24.126 \\
\hline & & LG & 87.129 & 0.885 & 24.789 \\
\hline & \multirow{2}{*}{ Laser2 } & HG & 94.871 & 2.447 & 22.890 \\
\hline & & LG & 89.555 & 0.913 & 22.533 \\
\hline \multirow{4}{*}{282} & \multirow{2}{*}{ Laser 1} & HG & 84.842 & 1.984 & 25.929 \\
\hline & & LG & 87.091 & 0.865 & 27.993 \\
\hline & \multirow{2}{*}{ Laser2 } & HG & 94.871 & 2.383 & 25.309 \\
\hline & & LG & 89.792 & 0.911 & 25.846 \\
\hline \multirow{4}{*}{320} & \multirow{2}{*}{ Laser1 } & HG & 84.520 & 2.055 & 25.617 \\
\hline & & LG & 87.316 & 0.981 & 25.984 \\
\hline & \multirow{2}{*}{ Laser2 } & $\mathrm{HG}$ & 94.945 & 2.535 & 24.174 \\
\hline & & LG & 89.750 & 0.934 & 23.603 \\
\hline \multirow{4}{*}{321} & \multirow{2}{*}{ Laser1 } & HG & 84.830 & 2.071 & 25.356 \\
\hline & & LG & 87.370 & 0.834 & 25.574 \\
\hline & \multirow{2}{*}{ Laser2 } & $\mathrm{HG}$ & 94.930 & 2.532 & 23.118 \\
\hline & & LG & 89.898 & 0.953 & 22.260 \\
\hline \multirow{4}{*}{337} & \multirow{2}{*}{ Laser1 } & $\mathrm{HG}$ & 84.818 & 1.947 & 25.020 \\
\hline & & LG & 87.339 & 0.823 & 24.724 \\
\hline & & $\mathrm{HG}$ & 94.932 & 2.496 & 22.588 \\
\hline & Laser2 & LG & 89.880 & 0.944 & 21.560 \\
\hline & & HG & 85.486 & 2.040 & 22.659 \\
\hline 344 & Laser 1 & LG & 87.688 & 0.895 & 21.309 \\
\hline
\end{tabular}

\begin{tabular}{|c|c|c|c|c|c|}
\hline \multirow{6}{*}{358} & \multirow{2}{*}{ Laser2 } & $\mathrm{HG}$ & 95.125 & 2.534 & 19.998 \\
\hline & & LG & 90.083 & 0.942 & 18.865 \\
\hline & \multirow{2}{*}{ Laser1 } & $\mathrm{HG}$ & 84.986 & 2.092 & 23.799 \\
\hline & & LG & 87.493 & 0.861 & 23.680 \\
\hline & \multirow{2}{*}{ Laser2 } & HG & 94.483 & 2.528 & 21.621 \\
\hline & & LG & 89.942 & 0.909 & 21.133 \\
\hline
\end{tabular}

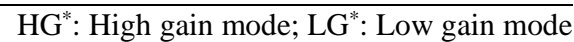
Table 4. The statistical result of the received waveform

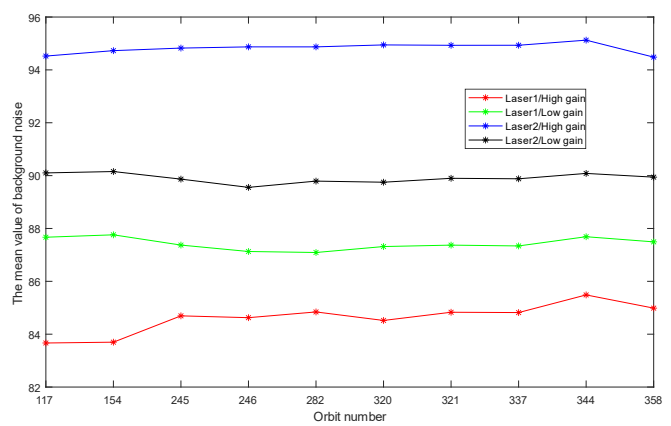

(a) Variation of the mean value of background noise

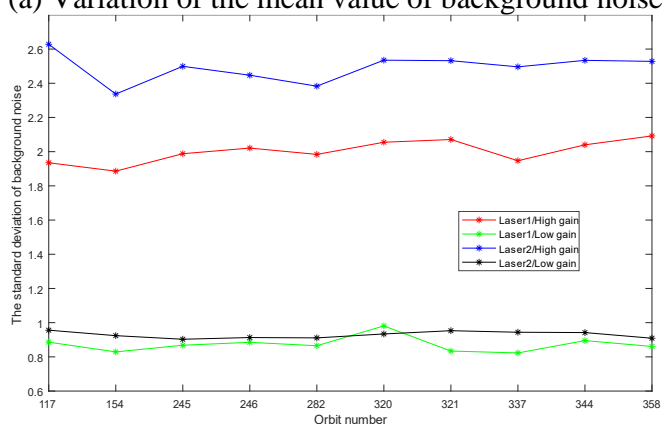

(b) Variation of the standard deviation of background noise 


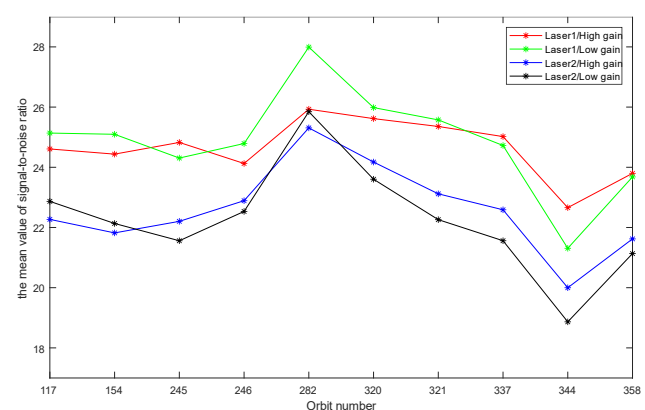

(c) Variation of the mean value of signal-to-noise ratio Figure 3. Analysis results of quality parameters of received waveform

\subsection{Statistics of the APD temperature}

The real-time temperature of APD has been recorded in GF-7 laser altimeter, which can be used to evaluate the state of the laser. In this paper, the relationship between the APD temperature and SNR of the transmitted waveform is illustrated in Figure 4. It is clear that SNR of the transmitted waveform can drop or decrease as the increase of APD temperature.

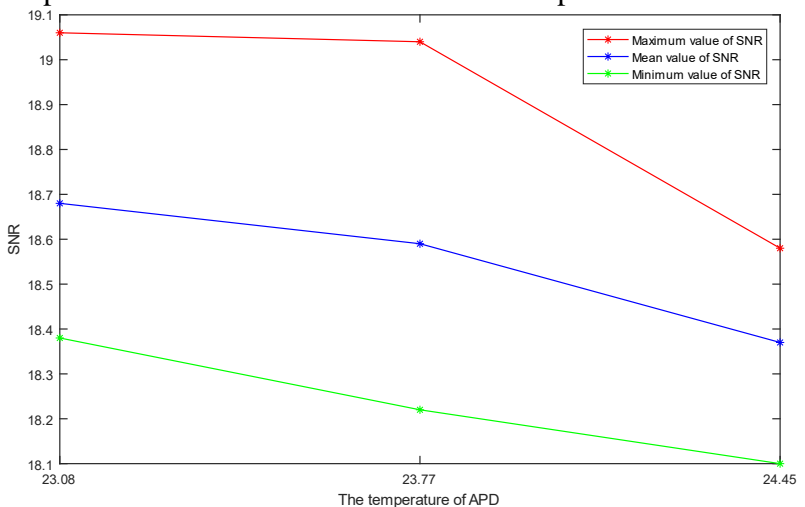

Figure 4. SNR of the transmitted waveform data at different APD temperatures (taking laser-2 as an example)

\section{SUMMARY AND PROSPECT}

Through the analysis of the waveform data obtaining during the period of on-orbit test of GF-7, the conclusions can be drawn as follows,

1) For the transmitting waveform, the mean value of the background noise of waveform varies in a similar trend between the high and low gain of the same laser, and the background noise of the waveform in high-gain mode is higher than that of low-gain mode. There is a correlation between the standard deviation of the background noise of waveforms in same gain mode of different lasers.

2) After the gaussian fitting of the transmitted waveform, the amplitude parameter has a most obvious variation among the gaussian parameters, and the maximum difference between the amplitude of the waveform in same gain of same laser that in different orbit is approaching 20, which mean the energy is variable. The peak location of the waveform has a maximum stability, whether in the same orbit or not, and the variation is less than $0.25 \mathrm{~ns}$. The RMS pulse width of the waveform of the transmitted waveform is very stable in the same orbit, and varies slightly from one orbit to the other, only within $0.1 \mathrm{~ns}$.

3) The calculation results of kurtosis value of the transmitted waveform show that the peak of the GF-7 transmitted waveform is slightly flat compared with the standard gaussian waveform, whereas, is not far from the standard gaussian. The kurtosis value is greater than 2.5. The mean of the skewness of waveform of every orbit is with $0 \sim 0.5$, indicating that the transmitted waveform is slightly skew to the right, and there is a good symmetry of the waveform yet.

4) In terms of the signal-to-noise ratio, the calculation method of SNR in this paper relies on the maximum intensity value of the waveform sampling point, while the maximum intensity value of the transmitted waveform is relatively small due to the different gain, thus, the SNR of the transmitted waveform is smaller than that of the received waveform. The SNR of the received waveform is affected by the terrain features, such as clouds, trees and vegetation, and the maximum of SNR of received waveform is 27.993 , and the minimum value is 18.865 , which shows a good reliability of the received waveform even it has the lower SNR. 5) The temperature of the APD will affect the quality of the transmitted waveform data, which can be used as an indicator to evaluate the state of the laser.

Quality evaluation and change monitoring

As the first laser altimeter for operational application of China, the GF-7 satellite laser altimeter with full waveform data can represent a new-era, although it has some distance with the GLAS and GEDI. After the on-orbit test, the GF-7 laser altimeter can be used to obtain the elevation control points for the stereo camera to realize the 1:10000 scale mapping, which will be exciting for the global mapping.

\section{ACKNOWLEDGEMENTS}

This work was supported by the Special Fund for High Resolution Images Surveying and Mapping Application System (Grant No: 42-Y30B04-9001-19/21) and the National Natural Science Foundation of China (Grant No: 41971425). The authors also thank the anonymous reviews for their constructive comments and suggestions.

\section{REFERENCES}

Brenner, A.C., Zwall, H. J., Bentley, C. R. 2011.Geo-science Laser Altimeter System: Derivation of Range and Range Distributions from Laser Pulse Waveform Analysis for Surface Elevations, Roughness, Slope, and Vegetation Heights. Algorithm Theoretical Basis Document, Version 5.0. University of Texas.

Bolch, T. , Sandberg SøRensen, L., Simonsen, S. B. , Machguth, H., and Rastner, P. , 2013. Mass loss of Greenlandl"s glaciers and ice caps 2003-2008 revealed from ICESat laser altimetry data. Geophysical Research Letters, 40(5):875-881.

Carabajal, C. C., Harding, D. J., Suchdeo, V. P., 2010. Development of AN ICESat Geodetic Control Database and Evaluation of Global Topographic Assets. American Geophysical Union, Fall Meeting 2010.

Harding, and David, J. 2005. ICESat waveform measurements of within-footprint topographic relief and vegetation vertical structure. Geophysical Research Letters, 2005, 32(21):L21S10.

Kääb, A., Berthier E, Nuth, C., Gardelle, J. and Arnaud, Y. , 2012. Contrasting patterns of early twenty-first-century glacier mass change in the Himalayas.Nature,488(7412):495 498.

Li, G. Y., 2017. Earth observation satellite laser altimetry data processing and project practice. Wuhan: Wuhan University.

Li, G. Y., Tang, X. M., 2017. Analysisand Validation of ZY-3 02 Satellite Laser Altimetry Data. Acta Geodaeticaet Cartographica Sinica,46(12):1939-1949. 
Li, G. Y., Tang, X. M., Zhang, C. Y., Gao, X. M.,and Chen, J. Y., 2017. Multi-criteria Constraint Algorithm for Selecting ICESat/GLAS Data as Elevation Control Points. Journal of Remote Sensing, 21(1):96-104.

Li, H. P., Li, G. Y., Cai, Z. J.,and Wu, G. H., 2019. Fullwaveform LiDAR echo decomposition method. Journal of Remote Sensing, 23(1): 89-98.

Li,S., Zhou, H., Shi, Y.and Guo, Y., 2007.Theoretical model for return signal of laser altimeter.Optics and Precision Enginee ring,2007(01): 33-39.

Nie, S., Wang, C., Li, G., Pan, F., Xi, X.and Luo, S., 2014. Signal-to-noise ratio-based quality assessment method for ICESat/GLAS waveform data. Optical Engineering, 53(10):103104

Tang, X. M., Li, G. Y., 2017. The Development and Prospective of Laser Altimeter Satellite. Space International,(11):13-18.

Wang, C., Zhu, X., Nie, S., Xi X., Li, D., Zheng, W., Chen S.,2019. Ground elevation accuracy verification of ICESat-2 data: a case study in Alaska, USA. Optics express,27(26).

Wang, X. , Cheng, X. , Li, Z. , Huang, H. , Niu, Z. and Li, X. , 2012. Lake Water Footprint Identification From Time-Series ICESat/GLAS Data. IEEE Geoscience and Remote Sensing Letters, 9(3):333-337.

Xing, Y., Gier, A.D., Zhang, J.and Wang, L., 2010. An improved method for estimating forest canopy height using ICESat-GLAS full waveform data over sloping terrain: A case study in Changbai mountains, China. International Journal of Applied Earth Observation and Geoinformation, 12(5):385-392.

Zhang, G., Xie, H.and Kang, S., 2011. Monitoring lake level changes on the Tibetan Plateau using ICESat altimetry data (2003-2009). Remote Sensing of Environment, 115(7):17331742 . 